\title{
HbA1c AND LIPID PROFILE; \\ CORRELATION WITH THE COMPLEXITY OF CORONARY ARTERY DISEASE
}

1. PG Student

Department of Cardiology

Isra University Hospital, Hyderabad.

2. Associate Professor,

Department of Cardiology

Isra University Hospital, Hyderabad.

3. Associate Professor

Department of Cardiology

Peoples Medical University

Shaheed Benazirabad.

4. Medical Officer

Indus Medical College

Tando Muhammad Khan.

5. Medical Officer

Indus Medical College

Tando Muhammad Khan.

6. Professor,

Department of Cardiology

Isra University Hospital, Hyderabad.

Correspondence Address:

Dr. Faraz Farooq Memon

PG Student

Department of Cardiology

Isra University Hospital, Hyderabad.

farazkashif@yahoo.com

Article received on:

02/12/2016

Accepted for publication:

25/03/2017

Received after proof reading:

06/05/2017

INTRODUCTION

Diabetes mellitus is a chronic long standing disease which has a significant role in the development and worsening of coronary artery disease other than the most common systemic involvements. Abnormally raised in the blood sugar levels persistently may increase the incidence of coronary artery disease (CAD) in otherwise healthy population. Previously published data suggest that atherosclerosis, formation and deposition of lipids in vessels, is enhanced after the patients diagnosed with diabetes mellitus and if not properly controlled may lead to its chronic disabilitating complications such as myocardial infarction and stroke. ${ }^{1}$

Mortality due to CAD in North America and Western Europe in the last decades has effectively reduced by a good health care system. ${ }^{2,3}$ But, it has expanded in the Asia mainly due to lack of awareness, unhealthy life style and poor health care system. ${ }^{4}$ Diabetes and Dyslipidemia has been major risk factors for the development of CAD around the world as well as in Pakistan.

Most of the cardiovascular diseases are caused by the underlying presence of atherosclerotic changes which starts since adulthood and increase in the burden of atherosclerosis can be caused by some already known modified and non-modifiable risk factors in which diabetes mellitus has a major role. Proper recognition of these underlying risk factors is very useful in prevention and cardiovascular disease in both man and women.

An angiographic based grading tool is designed with a name of SYNTAX score system to determine the complexity of coronary artery disease and to decide which patient gets benefit from CABG or $\mathrm{PCl}$. One of a very famous SYNTAX trial which has been conducted recently has observed the outcome of patients with multivessel coronary artery disease along with involvement of left main 
narrowing with coronary artery bypass grafting. In their study, they have found that patients with SYNTAX score greater than 34 were benefitted from $C A B G$ rather than $\mathrm{PCl}$ and in those patients whose SYNTAX score lower than 34 with a significant coronary artery disease was just as good for major adverse cardiac events, with lower stroke rates.

Previously, only one study has been conducted in Japan to determine the relationship between the complexities of coronary artery disease (CAD) with $\mathrm{HbA1c}$. But there is no international or national scientific data available that has shown relationship between the complexities of CAD with Lipid profile. So, this study has been conducted to fill the present scientific gap and to determine the causative underlying factor associated with complexity of CAD which will ultimately help us in further management of patients.

\section{PATIENTS AND METHODS}

This is a descriptive case series study conducted at Isra University Hospital Hyderabad in the department of Cardiology for duration of six months through consecutive patient selection sampling technique.

We have evaluated a total of 112 patients having age $\geq 25$ and $\leq 80$ years and undergoing for coronary angiography for the first time of either gender given consent to participate. Patients with renal impairment (Creatinine clearance $<60$ $\mathrm{ml} / \mathrm{min}$ ) and having history of Coronary Artery Bypass Grafting (CABG) or prior Percutaneous Coronary Intervention $(\mathrm{PCl})$ were excluded from the study.

\section{DATA ANALYSIS}

After careful review of inclusion and exclusion criteria a detailed history was taken from the patient before undergoing coronary angiography and then Syntax score was calculated using the available online calculator http://www. syntaxscore.com/calc/start.htm.

A 10cc blood samples were obtained from an overnight fast (12 hours) for determining the levels of blood glucose, $\mathrm{HbA} 1 \mathrm{C}$, and lipid profile including total cholesterol, High density lipoprotein cholesterol (HDL-C), low density lipoprotein cholesterol (LDL-C), and serum triglycerides.

All patients were screened for Diabetes mellitus and were labeled as Diabetic when the fasting blood glucose levels were $\geq 126 \mathrm{mg} / \mathrm{dl}$ or random blood glucose levels were $\geq 200 \mathrm{mg} / \mathrm{dl}$ or patient were already taking anti-diabetic drugs.

Before coronary angiography informed written consent was taken by patient and family members after explaining about all the risks and complications. Typically all the cases of coronary angiography were performed on General Electrical (GE) Innova 2000 U.S.A through the femoral artery in angiography department at Isra University Hospital, Hyderabad.

Statistical Package for the Social Sciences version 19 (SPSS V.19) was used for data entry and analysis. Categorical data like gender is presented as frequencies and percentages, whereas age, HbA1C levels, and lipid profile measurements are presented as mean \pm standard deviation. Age groups were equally divided into three categories, Younger (30-45 years), middle (46-60 years), and old (61-75 years). Based on the WHO criteria the $\mathrm{HbA} 1 \mathrm{C}$ levels were labeled normal when levels were $<6.5 \%$ and impaired when $\geq 6.5 \%$. Total cholesterol, HDL-C, LDL-C, and serum triglycerides were also divided into two categories, normal and impaired, based on the ATP III lipid profile guidelines. Association of syntax score with $\mathrm{HbA1C}$, total cholesterol, HDL-C, LDL-C, and serum triglycerides were analyzed by using Independent sample t-test and ANOVA tests where needed and presented as comparing bar charts and a $p$ value of $<0.05$ was taken as statistically significant. The data is presented in the form of tables, pie chart, and bar diagrams.

\section{RESULTS}

A total of 112 patients were selected for this study. The study subjects consisted of 76 males $(67.86 \%)$ and 36 (32.14\%) females. The mean age of patients was 54.16 years (9.74 \pm SD). Table-I. 
Show descriptive analysis of continuous variables including their means and standard deviations, SYNTAX Score (15.22 \pm 10.16$)$, Total Cholesterol (138.35 \pm 35.85), HDL-C $(27.6 \pm 6.76)$, LDL-C (92.39 \pm 34.68$)$, Triglycerides (164.71 \pm 94.07), and $\mathrm{HbA} 1 \mathrm{C}(6.66 \pm 2.29)$.

\begin{tabular}{|l|c|c|}
\hline \multicolumn{1}{|c|}{ Variables } & Mean & $\begin{array}{c}\text { Standard } \\
\text { Deviation }\end{array}$ \\
\hline SYNTAX Score & 15.22 & 10.16 \\
\hline Total Cholesterol - mg/dl & 138.35 & 35.85 \\
\hline HDL-C - mg/dl & 27.6 & 6.76 \\
\hline LDL-C - mg/dl & 92.39 & 24.68 \\
\hline Triglycerides - mg/dl & 164.71 & 94.07 \\
\hline HbA1C - \% & 6.66 & 2.29 \\
\hline
\end{tabular}

Table-I. Descriptive statistics of continuous variables

When comparing the SYNTAX score observed in our study with respect to three different age groups, analysis from this study showed significantly high mean of SX score $(20.5 \pm 12.1$, $p$ value 0.01 ) among older age group population than younger $(13.8 \pm 10.1)$ and middle $(13.9 \pm 9)$ age groups [Presented via Figure-1].

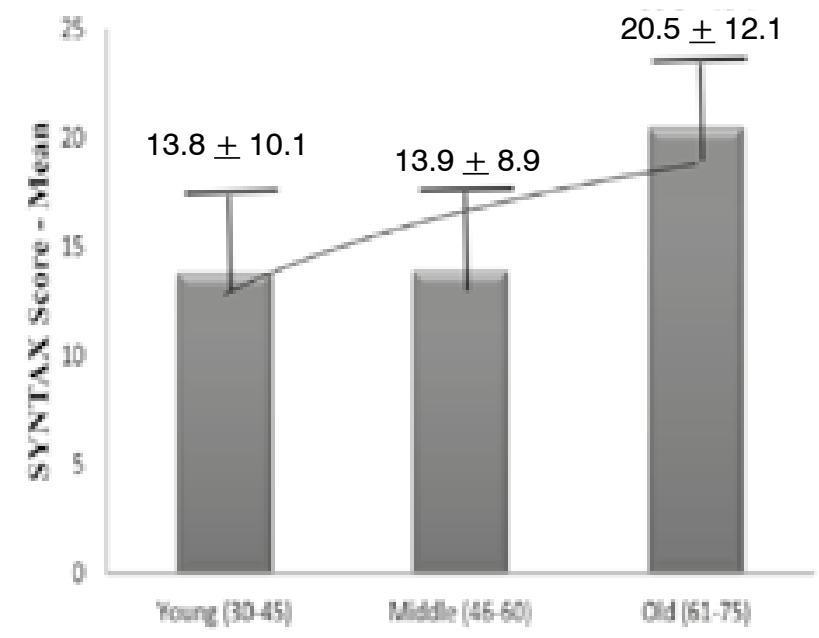

Figure-1. Comparison of Gender with SYNTAX Score

The main objective of this study was to find out the association of SX score with $\mathrm{HbA} 1 \mathrm{C}$ and different parameters of lipid profile.

Patients with increased $\mathrm{HbA} 1 \mathrm{C}(\geq 6.5 \%)$ and triglyceride levels $(\geq 150 \mathrm{mg} / \mathrm{dl})$ and decreased HDL-C levels ( $\leq 40 \mathrm{mg} / \mathrm{dl}$ ) were tend to have high Sx score. However, we did not find any significant relationship of SX score with total cholesterol and LDL-C levels [Presented via Figure- 2,3,4,5 and $6]$.

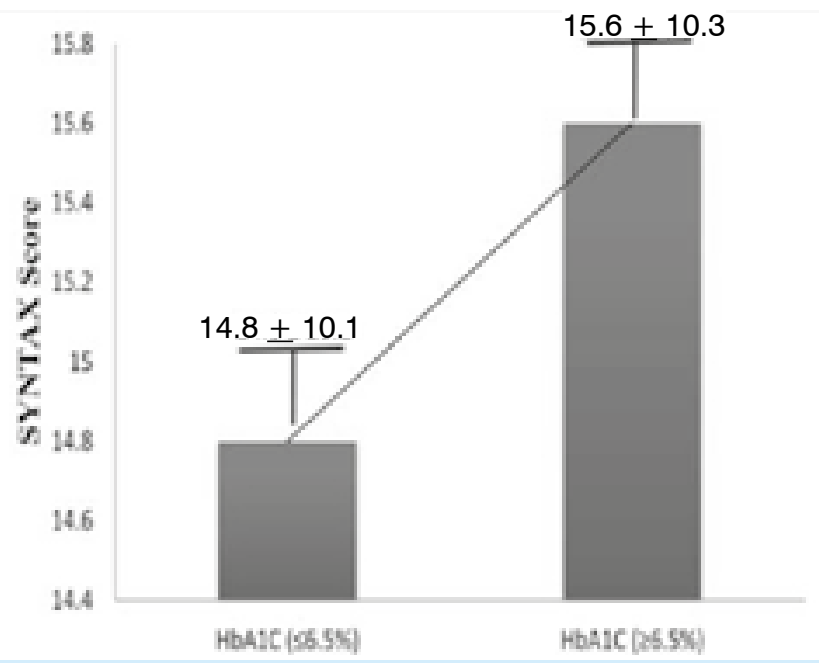

Figure No: 2. Comparison of SYNTAX with HbA1C

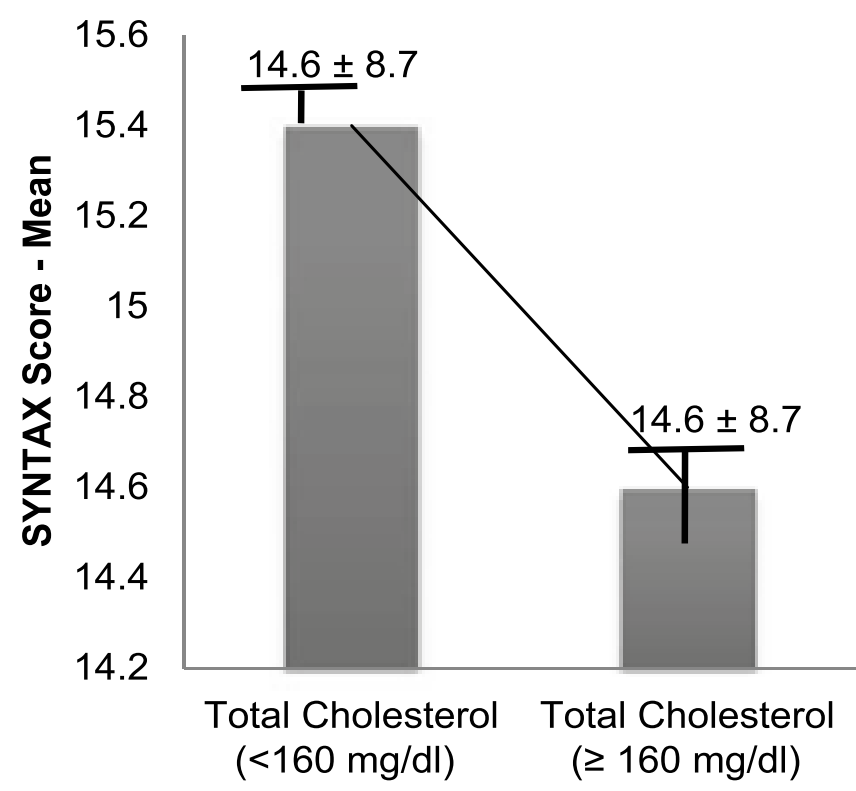

Figure-3. Comparison of SYNTAX with Total Cholesterol levels

\section{DISCUSSION}

Our present study is the first scientifically done to determine the Correlation of Glycosylated Hemoglobin and Lipid Profile with the complexity of Coronary Artery Disease in a Pakistani population. 


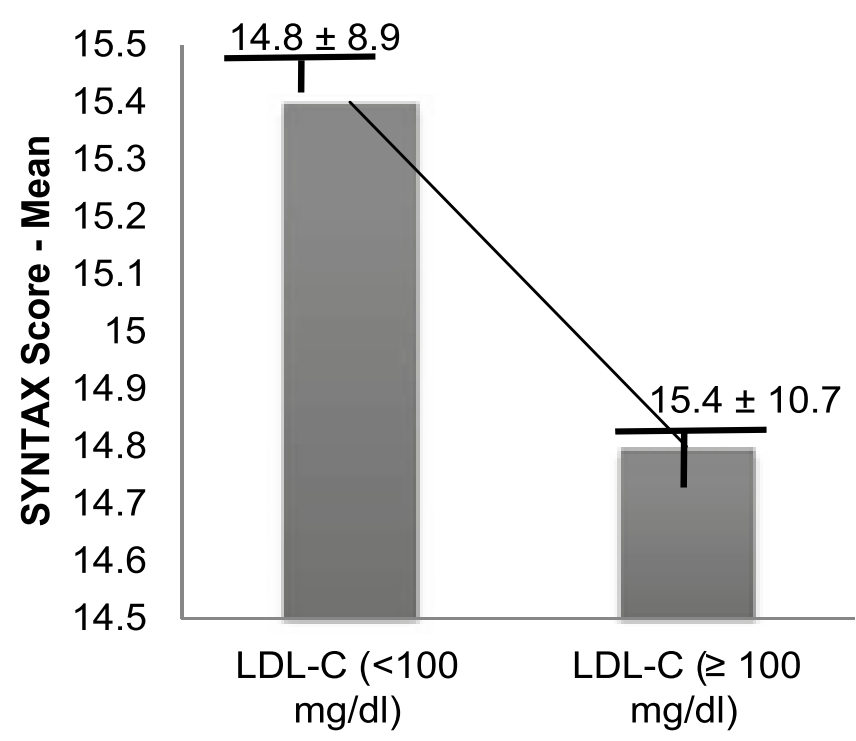

Figure-4. SYNTAX with LDL-C

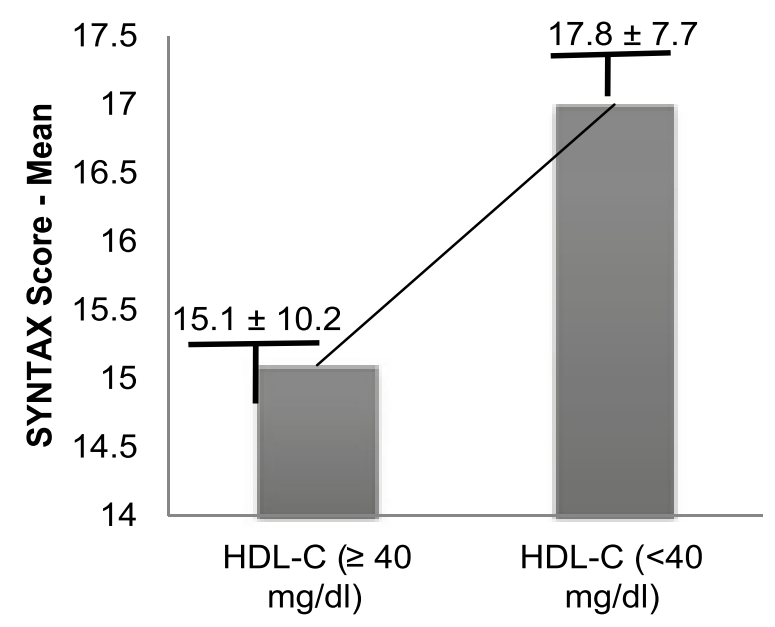

Figure-5. SYNTAX with HDL-C

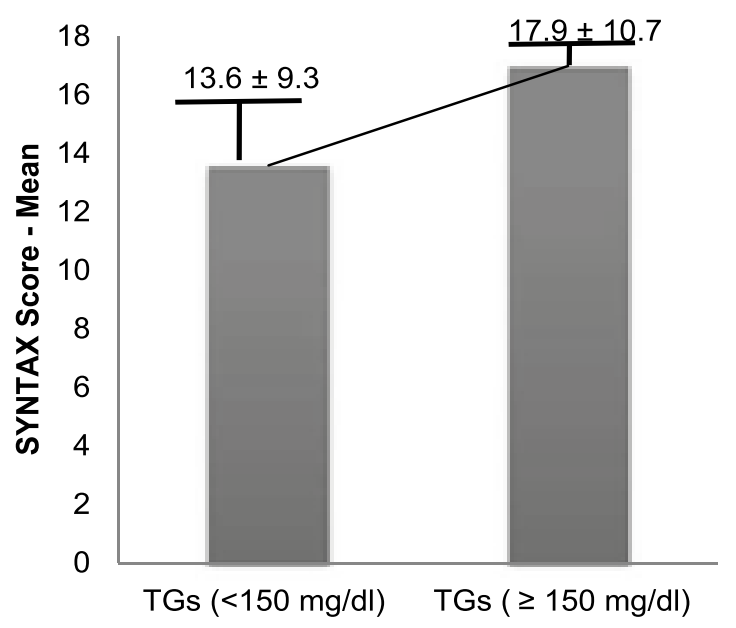

Figure-6. SYNTAX with TGs
For cardiologists and cardiothoracic surgeons the SYNTAX score is the only coronary artery disease severity predictive score to determine the postoperative outcome of patients after CABG in which left main coronary artery is involved. Majority of the previously conducted studies has shown that patients with higher SYNTAX score are least favorable for $\mathrm{PCl}$ than $\mathrm{CABG}$ and there are more chances of developing myocardial infarction, target lesion revascularization, and death more than double.

The previous study shows that in patients with ULMCA, the presence of a SYNTAX score $>34$ is associated with a higher risk of death after $\mathrm{PCl}$ compared with that of patients treated with CABG. In particular, after adjustment for potential confounders, patients with a SYNTAX score $>34$ treated with $\mathrm{PCl}$ had an almost 3-fold increase in the likelihood of 2-year mortality, whereas no differences between $\mathrm{PCl}$ and $\mathrm{CABG}$ outcomes were noted among patients with a SYNTAX score $\leq 34$. Overall, these findings support the hypothesis that a SYNTAX score threshold of 34 is clinically useful to select patients with left main disease who benefit most from revascularization by CABG. Importantly, a sensitivity data analysis showed that these findings are consistent irrespective of the disease location (e.g., ostium/ shaft or bifurcation) within the left main.

Diabetes and coronary artery disease (CAD) frequently coexist, leading to additive increases in the risk of life-threatening cardiovascular events. Coronary artery disease is a common comorbids condition in patients with type 2 diabetes when compared with the general population.

In our study mean and SD of age was 54.16 years (9.74 \pm SD) and among them male percentage was noticed higher compared to female ones $67.86 \% \%$ vs. $32.14 \%$, respectively. This favors that most of the study population based on middle aged population. There is no bigger difference in the basic demographics of patients with coronary artery disease in our study and when it compared with the studies conducted nationally and internationally. 
The mean SYNTAX score in our study was 15.22 which is almost favors revascularization vs. CABG in our study population. But in a previously published data their mean SYNTAX score was 26.3. This significant difference in the mean SYNTAX score could be due to their underlying presence of risk factors such as Dyslipidemia and uncontrolled diabetes mellitus and hypertension.

A systemic review and meta-analysis has been conducted in which data were compiled from seven different clinical trials of patients more than 6500 has shown that SYNTAX score was an independent predictor of mortality and other revascularization related complications at one year regardless of their presentation.

When looking at the observations of our study in correlation with other parameters we have find out that patients with increased $\mathrm{HbA} 1 \mathrm{C}(\geq 6.5 \%)$ and triglyceride levels $(\geq 150 \mathrm{mg} / \mathrm{dl})$ and decreased HDL-C levels ( $\leq 40 \mathrm{mg} / \mathrm{dl}$ ) were tend to have high Sx score. However, we did not find any significant relationship of SX score with total cholesterol and LDL-C levels. More or less these findings of our study have also been observed in a previously conducted international study.

The anticipated outcome which has been taken through calculation from SYNTAX score after coronary angiography provides an economical advantage in the making of final decisions whether patients is a candidate for PCl or CABG. Our study now provide scientific data through which conclusion can be drawn from Southeast population that which group is more in a favor of $\mathrm{PCl}$ and or $\mathrm{CABG}$.

\section{CONCLUSION}

It was found that the trend of complexity of CAD increased with increasing age, high $\mathrm{HbA} 1 \mathrm{C}$, high LDL-C, high serum triglyceride, and low HDL-C levels.

\section{Copyright@ 25 Mar, 2017.}

\section{REFRENCES}

1. Hadaegh F, Harati H, Ghanbarian A, Azizi1 F. Prevalence of coronary heart disease among Tehran adults: Tehran Lipid and Glucose Study Eastern Mediterranean Health Journal, 2009;15, No. 1.

2. Fakhrzadeh $\mathrm{H}$, Bandarian $\mathrm{F}$, Adibi $\mathrm{H}$, Samavat $\mathrm{T}$, Malekafzali $\mathrm{H}$, Hodjatzadeh $\mathrm{E}$ and Larijani B. Coronary heart disease and associated risk factors in Qazvin: a population-based study, Eastern Mediterranean Health Journal, 2008; 14, No. 1.

3. Stocker R, John F, Keaney J. Role of Oxidative Modifications in Atherosclerosis, Physiol. Rev. 2004;84: 1381-1478.

4. Freitas A, Mendonça I, Brión M, Sequeira M, Reis R, Carracedo $A$ and Brehm A. RAS gene polymorphisms, classical risk factors and the advent of coronary artery disease in the Portuguese population BMC Cardiovascular Disorders 2008; 8:15 doi:10.1186/1471-2261-8-15.

5. Maren S. Genetic evaluation for coronary artery disease. Genet Med: 2003;5(4):269.285.

6. Yamaguchi T, Horio F, Hashizume T, Tanaka M, Ikeda S, Kakinuma $A$, Nakajima $\mathrm{H}$. Bilirubin is oxidized in rats treated with endotoxin and acts as a physiological antioxidant synergistically with ascorbic acid in vivo. Biochem Biophys Res Commun, 1995;214:11.9.

7. Irene M Stratton, Amanda I Alder et al. Association of glycemia with macrovascular and microvascular complications of type 2 diabetes (UKPDS 35); Brit Med J. 2000 Vol 321 : 405-416.

8. Selvin E, Marinopoulos S, Berkenblit G, Rami T, Brancati FL, Powe NR, et al. Meta-analysis: glycosy-lated hemoglobin and cardiovascular disease in diabe-tes mellitus. Ann Intern Med 2004; 14: 421-431.

9. Khaw KT, Wareham N, Bingham S, Luben R, Welch $A$ and Day N. Association of hemoglobin A1c with car-diovascular disease and mortality in adults: the Euro-pean Prospective Investigation into Cancer in Norfolk. Ann Intern Med 2004; 141: 413-420.

10. Walden C, Knopp R, Wahl P, Beach K, Strandness E. Sex differences in the effect of diabetes mellitus on lipoprotein triglyceride and cholesterol concentrations. N Engl J Med 19184; 311:953-959.

11. America Diabetes Association. Dyslipidemia management in adult with diabetes. Diabetes care, 2004;24, 68-71.

12. Ellis SG, Vandormael MG, Cowley MJ, Whitlow PL, Schneider JP, Topol EJ. Coronary morphologic and clinical determinants of procedural outcome with angioplasty for multivessel coronary disease. Implications for patient selection. Multivessel 
Angioplasty Prognosis Study Group. Circulation 1990; 82: 1193-1202.

13. Gyöngyösi M, Christ G, Lang I, Kreiner G, Sochor H, Probst P, et al. Two-year results of the AUTAX (Austrian Multivessel TAXUS-Stent) registry beyond the SYNTAX (synergy between percutaneous coronary intervention with TAXUS and cardiac surgery) study. JACC Cardiovasc Interv 2009; 2: 718-727.

14. Valgimigli M, Serruys PW, Tsuchida K, Vaina S, Morel $M A$, vanden Brand $M J$, et al. Cyphering the complexity of coronary artery disease using the Syntax score to predict clinical outcome in patients with threevessel lumen obstruction undergoing percutaneous coronary intervention. Am J Cardiol 2007; 99: 10721081.

15. Hlatky MA, Boothroyd DB, Bravata DM, BoersmaE, Booth
J, Brooks MM, et al. Coronary artery bypass surgery compared with percutaneous coronary interventions for multivessel disease: a collaborative analysis of individual patient data from ten randomised trials. Lancet 2009; 373: 1190-1197. 17.

16. Benedetto U, Melina G, Angeloni E, Refice S, Roscitano $A$, Fiorani $B$, et al. Coronary artery bypass grafting versus drug-eluting stents in multivessel coronary disease: a meta-analysis on 24268 patients. Eur J Cardiothorac Surg 2009; 36: 611-615. 18.

17. Park DW, Yun SC, Lee SW, Kim YH, Lee CW, Hong MK, et al. Long-term mortality after percutaneous coronary intervention with drug-eluting stent implantation versus coronary artery bypass surgery for the treatment of multivessel coronary artery disease. Circulation 2008; 117: 2079-2086.

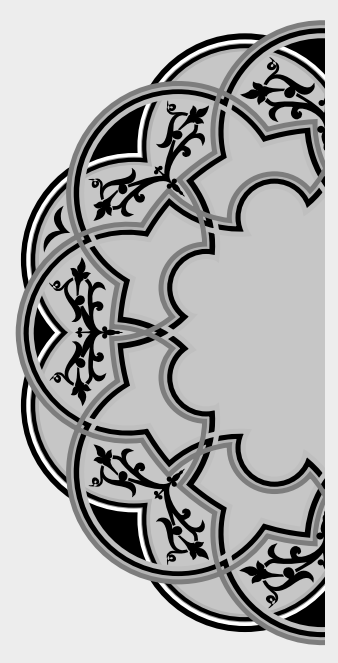

"A negative mind will never give you a positive life."

\author{
Unknown
}

\section{AUTHORSHIP AND CONTRIBUTION DECLARATION}

\begin{tabular}{|c|l|l|}
\hline Sr. \# & \multicolumn{1}{|c|}{ Author-s Full Name } & Contribution to the paper \\
\hline 1 & Dr. Faraz Farooq Memon & Author=s Signature \\
2 & Dr. Nandlal Rathi & All authors have contributed \\
3 & Dr. Qurban Ali Rahoo & equally. \\
4 & Dr. Bhunesh Maheshwari & Dr. Mariya Maheshwari \\
5 & Dr. Feroz Memon & \\
6
\end{tabular}

